\title{
Inequalities in cycle helmet use: cross sectional survey in schools in deprived areas of Nottingham
}

\author{
D Kendrick, S Royal, on behalf of the "Lids for Kids" project team
}

Arch Dis Child 2003;88:876-880

See end of article for authors' affiliations

.....................

Correspondence to: Dr D Kendrick, Division of General Practice, University Park Nottingham NG7 2RD UK;

denise.kendrick@ nottingham.ac.uk

Accepted

18 January 2003

\begin{abstract}
Aims: To describe cycle helmet owning and wearing among children in a deprived area and to investigate the association between helmet ownership and wearing and socioeconomic deprivation. Methods: Cross sectional survey in 28 primary schools in deprived areas of Nottingham; 1061 year 5 schoolchildren were studied.

Results: All year 5 children attending school on the day of the survey completed the questionnaire (87\% of children registered at participating schools). Children residing in a deprived area were less likely to own a bike and more likely to ride it four days a week or more. Half the children owned a helmet $(52 \%)$, but only $29 \%$ of these always wore their helmet. Children in deprived areas were less likely to own a helmet, but those that owned a helmet were not less likely to always wear one. Family encouragement and parental warning of dangers of not wearing a helmet were associated with increased helmet ownership rates. Family encouragement and best friends wearing a helmet were associated with higher rates of helmet wearing.

Conclusions: Programmes aimed at preventing head injury among child cyclists will need to address the inequality in helmet ownership that exists between children residing in deprived and non-deprived areas. Strategies to increase family encouragement to wear a helmet may be useful, as may those recognising the importance of the attitudes and behaviours of peers, such as peer education programmes. Further work is required to assess how exposure to risk of cycling injury varies with deprivation.
\end{abstract}

\section{METHODS}

All junior schools in wards with Townsend scores above zero were invited to participate in the trial $(\mathrm{n}=120)$ and 30 agreed to participate. One school acted as a pilot and one withdrew prior to the baseline survey. A cross sectional survey of year 5 children (aged 9 and 10) in the 28 participating schools was undertaken using a self completion questionnaire. The Queen's Medical Centre Ethics Committee confirmed that ethical approval was not required as the participants were schoolchildren, not patients.

\section{Questionnaire design}

The questionnaire was based on questions taken from a Bicycle Helmet Trust Initiative questionnaire ${ }^{6}$ and from a questionnaire previously used with secondary school children in the UK. ${ }^{3}$ It included questions on age, sex, postcode, bicycle ownership, bicycle riding, helmet ownership and wearing, reasons for deciding whether to wear a helmet or not, encouragement to wear a helmet by others, best friends helmet wearing, cycling accidents, effect of a helmet law on bike riding, and reasons why young people do or do not wear helmets. The questionnaire was piloted on 30 children in year 5 in a school not taking part in the project. Only minor word changes resulted from the pilot.

\section{Questionnaire administration}

The questionnaire was distributed to all participating schools; year 5 teachers asked all children present in class on the day of the survey to complete the questionnaire. All questionnaires were completed in the week beginning 4 June 2001. If children did not know their postcode the questionnaire told them to ask their teacher for help, and the teacher supplied the postcode from the school records.

\section{Data handling, sample size, and analysis}

Data were entered into an Access database. A random sample of $10 \%$ of questionnaires was double entered and discrepancies identified. Only $0.97 \%$ of keystrokes differed between the two sets of double entered questionnaires. Any discrepancies identified were corrected. The Townsend score was used to measure deprivation at the enumeration district level. The 
Table 1 Bike ownership, frequency of bike riding, and helmet ownership

\begin{tabular}{ll}
\hline & Frequency (percentage) \\
\hline Male & $533(50.2)$ \\
Median Townsend score (range) & $0.81(-5.7$ to 8.5$)$ \\
Resides in deprived area* & $518(57.6)[161]$ \\
Owns bike & $955(90.0)$ \\
Rides bike & {$[16]$} \\
Daily & $190(20.2)$ \\
4-6 days per week & $319(34.0)$ \\
$1-3$ days per week & $201(21.4)$ \\
Less than once a week & $150(16.0)$ \\
Less than once a month & $79(8.4)$ \\
Rides bike & \\
To and from school & $23(2.4)$ \\
To visit friends & $484(50.7)$ \\
For fun & $837(87.6)$ \\
Only when has to & $87(9.1)$ \\
For sport & $336(35.2)$ \\
Owns helmet $\dagger$ & $495(51.8)$ \\
Wears helmet when riding $\ddagger$ & {$[8]$} \\
Always & $142(29.2)$ \\
Sometimes & $234(48.1)$ \\
Never & $111(22.8)$ \\
Wears helmet when riding $\ddagger$ & \\
On the road or street & $317(64.0)$ \\
In garden or yard & $77(15.6)$ \\
To and from school & $26(5.3)$ \\
Off road & $240(48.5)$ \\
On cycle route & $180(36.4)$ \\
In park & $194(39.2)$ \\
\hline Missing values in square brackets. & \\
*Defined as Townsend score $>0$. & \\
$\dagger \%$ of those who own a bike; $¥ \%$ of those owning helmet. \\
\end{tabular}

study had $80 \%$ power at the $5 \%$ significance level to detect a difference of 17 percentage points in helmet ownership, based on $44 \%$ of children in deprived areas owning a helmet, and an intraclass correlation coefficient of 0.06 , which was calculated from the data. It had $80 \%$ power at the $5 \%$ significance level to detect a difference of 15 percentage points in helmet wearing, based on $27 \%$ of children residing in deprived areas wearing a helmet, and an intraclass correlation coefficient of 0.02, which was calculated from the data. Data were analysed using SPSS version 10 and STATA version 7 . Univariate and multivariate analyses investigating factors associated with helmet ownership and wearing were undertaken using logistic regression with robust standard errors to adjust for clustering. ${ }^{78}$ Covariates were included in the multivariate model only if they resulted in a significant improvement in the fit of the model. The relation between deprivation and factors associated with helmet ownership and wearing was examined using likelihood ratio tests comparing models with and without interaction terms. Residuals were plotted to check the models. Significance has been assessed at the $1 \%$ level. Analyses of helmet ownership were restricted to children owning a bike and analyses of helmet wearing to those owning a helmet. Children reporting they always wore a helmet have been compared to those sometimes or never wearing a helmet to minimise the effect of potential over reporting of helmet wearing.

\section{RESULTS}

There were 1226 year 5 children registered at participating schools. Completed surveys were obtained from all 1061 children in year 5 attending school on the day of the survey $(87 \%$ of all registered children). Tables 1 and 2 show that the majority of children owned bikes $(90 \%)$ and that more than half rode their bikes four days a week or more $(54 \%)$. Children most commonly rode to visit friends or for fun; very few rode to school $(2 \%)$. Although half the children owned a helmet $(52 \%)$, only $29 \%$ of these always wore their helmet. Fewer than half the children $(40 \%)$ said their parents encouraged them to wear a helmet. They had most frequently been told of the dangers of not wearing a helmet by parents, teachers, and road safety officers. Fewer than one fifth (17\%) said their best friend wore a helmet. Almost one in five (19\%) had had a bicycle accident resulting in an injury, which required medical attention. Only $5 \%$ said they would stop riding their bike if a law was made to enforce helmet wearing.

\section{Deprivation and helmet ownership and wearing}

Children living in a deprived area were less likely to own a bike ( $87 \%$ versus $94 \%$, odds ratio (OR) $0.47,95 \%$ confidence interval (CI) 0.28 to $0.80, p=0.005$ ) and more likely to ride it four days a week or more ( $56 \%$ versus $49 \%$, OR $1.35,95 \%$ CI 1.09 to $1.68, \mathrm{p}=0.006)$. Children in deprived areas were less likely to own a helmet ( $44 \%$ versus $56 \%$, OR $0.47,95 \%$ CI 0.31 to 0.70 , $\mathrm{p}<0.001$ ), but those that owned a helmet were not less likely

Table 2 Frequency of factors that may influence helmet wearing

\begin{tabular}{ll}
\hline & Frequency (percentage) \\
\hline Important or very important reasons for wearing helmet & \\
How comfortable helmet feels & $735(70.1)[12]$ \\
How helmet looks & $331(31.6)[14]$ \\
Helmet could save life & $995(94.5)[1]]$ \\
What friends think and say & $250(24.2)[30]$ \\
Wearing helmet is good way of protecting head if fall off bike & $983(95.1)[27]$ \\
Encouraged by family members to wear helmet* & $367(40.0)[37]$ \\
Told about dangers of not wearing helmet by: & \\
Parent & $829(78.1)$ \\
School nurse & $95(9.0)$ \\
Teacher & $705(66.5)$ \\
Doctor & $183(17.3)$ \\
Policeman & $269(23.4)$ \\
Road safety officer & $670(63.2)$ \\
No one & $49(4.6)$ \\
Other person & $225(21.2)$ \\
Best friend wears helmet & $176(17.3)[42]$ \\
Had accident on bike requiring medical attention & $200(18.9)$ \\
If it was made law to wear helmet would: & {$[41]$} \\
Carry on wearing helmet & $287(28.1)$ \\
Start wearing helmet & $680(66.7)$ \\
Stop riding bike & $53(5.2)$ \\
\hline Missing data points in square brackets. & \\
$* \%$ of those who own a bike. & \\
\hline
\end{tabular}


Table 3 Univariate and multivariate associations with helmet ownership

\begin{tabular}{|c|c|c|}
\hline & $\begin{array}{l}\text { Univariate analysis } \\
\text { Odds ratio }(95 \% \mathrm{Cl})\end{array}$ & $\begin{array}{l}\text { Multivariate analysis } \\
\text { Odds ratio }(95 \% \mathrm{CI})\end{array}$ \\
\hline Sex & 1.00 (0.75 to 1.33$), p=0.98$ & \\
\hline Residence in deprived area* & $0.47(0.31$ to 0.70$), p<0.001$ & $0.47(0.33$ to 0.69$), p<0.001$ \\
\hline Rides bike $\geqslant 4$ days per week & $0.61(0.49$ to 0.76$), p<0.001$ & $0.57(0.44$ to 0.74$), p<0.001$ \\
\hline \multicolumn{3}{|l|}{ Rides bike } \\
\hline To and from school & 0.85 (0.28 to 2.61$), p=0.78$ & \\
\hline To visit friends & 0.75 (0.58 to 0.98$), p=0.03$ & \\
\hline For fun & $1.22(0.78$ to 1.91$), p=0.38$ & \\
\hline Only when has to & $0.86(0.60$ to 1.22$), p=0.39$ & \\
\hline For sport & $1.16(0.90$ to 1.49$), p=0.27$ & \\
\hline \multicolumn{3}{|l|}{ Important or very important reasons for wearing helmet } \\
\hline How comfortable helmet feels & 0.86 (0.67 to 1.12$), p=0.26$ & \\
\hline How the helmet looks & 0.85 (0.62 to 1.17$), p=0.33$ & \\
\hline Helmet could save life & $1.13(0.56$ to 2.28$), p=0.73$ & \\
\hline What friends think and say & $0.89(0.60$ to 1.31$), p=0.56$ & \\
\hline Wearing helmet is good way of protecting head if fall off bike & $1.28(0.81$ to 2.03$), p=0.30$ & \\
\hline Encouraged by family members to wear helmet & 3.46 (2.53 to 4.72$), p<0.001$ & 2.67 (1.93 to 3.69$), p<0.001$ \\
\hline \multicolumn{3}{|l|}{ Told about dangers of not wearing helmet by: } \\
\hline Parent & $2.64(1.81$ to 3.85$), p<0.001$ & 2.09 (1.38 to 3.17$), p<0.001$ \\
\hline School nurse & $0.90(0.50$ to 1.61$), p=0.72$ & \\
\hline Teacher & $1.16(0.86$ to 1.56$), p=0.33$ & \\
\hline Doctor & $0.73(0.53$ to 1.00$), p=0.05$ & \\
\hline Policeman & 0.90 (0.68 to 1.18$), p=0.43$ & \\
\hline Road safety officer & $1.05(0.69$ to 1.60$), p=0.82$ & \\
\hline Other person & 1.57 (1.14 to 2.17 ), $p=0.006$ & \\
\hline Best friend wears helmet & $1.84(1.18$ to 2.85$), p=0.007$ & \\
\hline Had accident on bike requiring medical attention & $0.78(0.57$ to 1.07 ), $p=0.13$ & \\
\hline
\end{tabular}

to always wear one ( $27 \%$ versus $29 \%$, OR $0.90,95 \%$ CI 0.60 to $1.36, \mathrm{p}=0.63)$. Table 3 shows the odds ratios for factors associated with helmet ownership. The multivariate analysis shows that residence in a deprived area and riding a bike at least four days a week were associated with lower rates of helmet ownership, while family encouragement to wear a helmet and parental warning of the dangers of not wearing a helmet were associated with higher rates of helmet ownership. The relations between helmet ownership and frequency of riding $(p=0.51)$, family encouragement to wear a helmet $(p=0.91)$, and parental warning of dangers of not wearing a helmet $(p=0.95)$ were similar for children living in deprived and non-deprived areas.

Table 4 shows the odds ratios for helmet wearing. The multivariate analysis shows that family encouragement to wear a helmet, having a best friend who wears a helmet, and thinking helmet comfort is important were associated with higher rates of helmet wearing. Riding a bike to visit friends was associated with lower rates of helmet wearing. The relations between helmet wearing and riding a bike to visit friends

Table 4 Univariate and multivariate associations with helmet wearing

\begin{tabular}{|c|c|c|}
\hline & $\begin{array}{l}\text { Univariate analysis } \\
\text { Odds ratio }(95 \% \mathrm{Cl})\end{array}$ & $\begin{array}{l}\text { Multivariate analysis } \\
\text { Odds ratio }(95 \% \mathrm{Cl})\end{array}$ \\
\hline Sex & $0.90(0.58$ to 1.40$), p=0.65$ & \\
\hline Residence in deprived area* & $0.90(0.60$ to 1.36$), p=0.63$ & \\
\hline Rides bike $\geqslant 4$ days per week & $0.80(0.48$ to 1.32$), p=0.38$ & \\
\hline \multicolumn{3}{|l|}{ Rides bike } \\
\hline To and from school & $0.24(0.07$ to 0.82$), p=0.02$ & \\
\hline To visit friends & $0.62(0.41$ to 0.92$), p=0.02$ & $0.62(0.43$ to 0.89$), p=0.01$ \\
\hline For fun & $1.14(0.60$ to 2.19$), p=0.69$ & \\
\hline Only when has to & $1.29(0.72$ to 2.31$), p=0.39$ & \\
\hline For sport & $0.86(0.60$ to 1.24$), p=0.42$ & \\
\hline \multicolumn{3}{|l|}{ Important or very important reasons for wearing helmet } \\
\hline How comfortable helmet feels & $1.87(1.23$ to 2.84$), p=0.004$ & $1.68(1.12$ to 2.53$), p=0.01$ \\
\hline How the helmet looks & $0.59(0.38$ to 0.91$), p=0.02$ & \\
\hline Helmet could save life & $3.15(0.83$ to 12.05$), p=0.09$ & \\
\hline What friends think and say & $0.85(0.57$ to 1.27$), p=0.43$ & \\
\hline Wearing helmet is good way of protecting head if fall off bike & $4.49(1.11$ to 18.15$), p=0.04$ & \\
\hline Encouraged by family members to wear helmet & 7.45 (4.47 to 12.42$), p<0.001$ & 7.19 (4.22 to 12.25$), p<0.001$ \\
\hline \multicolumn{3}{|l|}{ Has been told about dangers of not wearing helmet by: } \\
\hline Parent & 2.01 (1.03 to 3.93 ), $p=0.04$ & \\
\hline School nurse & $0.74(0.44$ to 1.24$), p=0.26$ & \\
\hline Teacher & $0.84(0.57$ to 1.19$), p=0.33$ & \\
\hline Doctor & $1.17(0.69$ to 1.98$), p=0.55$ & \\
\hline Policeman & $0.94(0.64$ to 1.39$), p=0.76$ & \\
\hline Road safety officer & $0.94(0.60$ to 1.47$), p=0.79$ & \\
\hline Other person & $0.83(0.57$ to 1.22$), p=0.35$ & \\
\hline Best friend wears helmet & $2.89(1.77$ to 4.72$), p<0.001$ & 2.05 (1.18 to 3.57$), p=0.01$ \\
\hline Had accident on bike requiring medical attention & $0.79(0.54$ to 1.15$), p=0.21$ & \\
\hline
\end{tabular}


$(p=0.31)$, family encouragement to wear a helmet $(p=0.89)$, the importance of helmet comfort $(p=0.89)$, and best friends wearing a helmet $(p=0.10)$ were similar for children living in deprived and non-deprived areas.

\section{DISCUSSION \\ Principal findings}

Our study has found that children residing in deprived areas are less likely to own a bike, but those that do own bikes ride them more frequently than children in non-deprived areas. Helmet ownership is less common among children residing in a deprived area and those who ride their bikes most frequently. It is more common where there is family encouragement and where parents inform their children of the dangers of not wearing a helmet. These relations are similar for children residing in deprived and non-deprived areas. Once a helmet is owned, helmet wearing is not related to deprivation. Parental encouragement and best friends wearing helmets are associated with higher helmet wearing rates. Riding a bike to visit friends is associated with lower helmet wearing rates. Again these relations are similar for children residing in deprived and non-deprived areas.

\section{Limitations of the study}

Our study was confined to children in year 5 in order to facilitate the delivery of the educational intervention to be tested in the subsequent cluster randomised trial. This narrow age group probably does not represent the experiences of older secondary school children or younger primary school children, and the results should not be generalised to younger or older children. The questions asking about helmet wearing behaviour are most susceptible to misclassification. We have tried to minimise over reporting of helmet wearing by comparing children always wearing a helmet to those wearing a helmet less often, ${ }^{9}$ but while accepting that some over reporting may still have occurred there is disagreement about its extent in surveys of this type. One study comparing self reported helmet wearing with helmet wearing recorded in the medical records of injured cyclists found self report to have a positive predictive value of $96 \%,{ }^{10}$ although only $25 \%$ of the participants were children and self report may be more or less accurate in children than adults. The Seattle Children's Bicycle Helmet Campaign ${ }^{11}$ found observed baseline helmet use in the study population of $5.5 \%$, while a simultaneous questionnaire survey (response rate $48.5 \%$ ) completed by the parents of a sample of the same population suggested a helmet wearing rate of $13 \% .^{12}$ Another trial of a bicycle helmet promotion intervention found a similar level of parent reported helmet use $(15 \%)$ in a baseline survey compared with observed helmet wearing in the region of $1.6 \% \cdot{ }^{13}$ Interestingly two other trials appear to have found observed helmet wearing rates to have been similar or even higher than parent or child reported helmet use. ${ }^{14}{ }^{15}$ Even if our self reported helmet wearing does represent an over report, we have no reason to believe the over reporting differed by deprivation, hence it is unlikely to have biased our analyses in relation to deprivation.

We were unable to obtain Townsend scores for 161 children, of whom 146 owned a bike and 68 owned a helmet. This was due to children not knowing or incorrectly recording their postcode, and in one school the head teacher would only provide us with the ward in which the child lived, not the postcode. We undertook a sensitivity analysis, assuming firstly that all children with missing postcodes lived in a deprived area, and secondly that none of them lived in a deprived area. We then recalculated the odds ratios for helmet owning and wearing comparing children in deprived and non-deprived areas. The odds ratios and 95\% confidence intervals changed little from those for the main analysis for either helmet owning or wearing. Assuming all children with missing postcode data lived in a deprived area, the odds ratio for helmet ownership was 0.48 (95\% CI 0.31 to 0.72 ) and for helmet wearing was 0.97 (95\% CI 0.66 to 1.42 ). Assuming all children with missing postcodes lived in a non-deprived area, the odds ratio was 0.57 (95\% CI 0.41 to 0.79 ) for helmet owning and 0.87 (95\% CI 0.60 to 1.25 ) for helmet wearing. This suggests that had postcode data been available on these children, it would not lead us to alter our conclusions regarding the effect of deprivation on helmet ownership and wearing.

\section{How this study compares to other studies}

Two previous UK surveys in children of a similar age to our study population found helmet ownership rates of $69 \%$ in East Sussex $^{3}$ and 58\% in South Staffordshire ${ }^{16}$ higher than the 52\% found in our study. The first found $30 \%$ of 11 year olds reported always wearing a helmet, ${ }^{3}$ very similar to our findings. The second study found that $64 \%$ of helmet owners reported wearing them always or nearly always, ${ }^{16}$ higher than that found in our study. It is likely that we found a lower prevalence of helmet ownership as a result of selecting a population from schools in deprived areas. The higher helmet wearing rate in the South Staffordshire study may reflect the combining of the response categories always and nearly always, which is likely to lead to a less conservative estimate of wearing rates than that based on responses indicating the child always wears a helmet.

Our study is the first set in the UK to compare helmet ownership and wearing by deprivation, although work from the US supports our principal findings. The baseline data from two studies attempting to promote helmet use in low income children found higher rates of helmet use among more affluent socioeconomic groups. ${ }^{45}$ Two national (US) telephone surveys found that higher levels of parental education and household income were associated with increased levels of helmet ownership and wearing. ${ }^{17} 18$

The two previous UK surveys, ${ }^{316}$ a recent Finnish survey, ${ }^{19}$ and the Seattle Children's Bicycle Helmet Campaign ${ }^{12}$ highlighted the importance of friends and parents in influencing helmet wearing. Our study is the first to examine whether these influences on helmet ownership and wearing are related to deprivation. Our findings that parental encouragement and warning of dangers, and helmet use by friends have similar effects in terms of influencing helmet use in children residing in deprived and non-deprived areas are encouraging. The prevalence of parental encouragement (OR 0.81, 95\% CI 0.53 to $1.25, \mathrm{p}=0.35$ ) and warning of dangers (OR $0.86,95 \% \mathrm{CI}$ 0.52 to $1.44, \mathrm{p}=0.57$ ) did not differ between deprived and non-deprived areas, suggesting parental attitudes to helmet use are similar in deprived and non-deprived areas. Interventions aimed at increasing parental encouragement or peer group use of helmets are therefore important in both deprived areas and non-deprived areas.

There are concerns that cyclists wearing helmets may act in a more risky manner because of the sense of increased protection offered by the helmet. ${ }^{20-22}$ There are also concerns that increasing cycle helmet use, particularly through the use of legislation, may be associated with a reduction in cycling and in the health benefits associated with cycling. ${ }^{21}$ While we support programmes to increase cycle helmet use, cycle helmets are only one part of a strategy for reducing cycling injuries. Similarly, encouraging cycling can only ever form part of a strategy to promote child health.

\section{Implications}

Our study found that helmet ownership is less common among bicycle owning children in deprived areas. This may form part of the explanation for the inequality in cycling injuries. Programmes aimed at preventing cycling injuries will need to address the inequality in helmet ownership that exists between children residing in deprived and non-deprived 
areas. Strategies to increase family encouragement to wear a helmet may be useful, in both deprived and non-deprived areas, as may those recognising the importance of the attitudes and behaviours of peers, such as peer education programmes.

Our study also suggests that children in deprived areas ride their bikes more frequently than children in non-deprived areas, which may also partly explain the social gradient in cycle injuries. Further work is required in this area to assess other exposures to risk of cycling injury by deprivation.

\section{ACKNOWLEDGEMENTS}

We would like to thank Kath Needham the project administrator, plus the members of the "Lids for Kids" project team: Dr David Thomas, Dr Frank Coffey, Ms Kate Fletcher, Mr Roger Whitfield, Ms Hazel Hoskyns, Ms Sue Spanswick, Dr Stephanie Smith, and Ms Pauline Brown. We would also like to thank the children, teachers, and administrative staff at the participating schools and Ms Lindsay Groom and Dr Tim Coleman for commenting on drafts of the paper.

\section{Funding: Nottingham Health Authority.}

Contributions: Denise Kendrick had the original idea for the study, designed the study, obtained funding for the study, managed the project team, undertook the analyses, and wrote the methods, results, and part of the introduction and discussion sections of the paper. Simon Royal assisted in the design and implementation of the study, was a member of the project team, checked some of the analyses, and wrote the introduction and discussion sections of the paper.

\section{Authors' affiliations}

D Kendrick, S Royal, Division of General Practice, University Park, Nottingham, UK

\section{REFERENCES}

1 Thompson DC, Rivara FP, Thompson R. Helmets for preventing head and facial injuries in bicyclists. Cochrane Database Systematic Reviews 2000(2):CD001855

2 Cook A. Sheikh A. Trends in serious head injuries among cyclists in England: analysis of routinely collected data. BN 2000;321:1055.
3 Cryer PC, Cole J, Davidson LL, et al. Rates of, and the factors affecting, cycle helmet use among secondary schoolchildren in East Sussex and Kent. Inj Prev 1998;4:106-10

4 Farley C, Haddad S, Brown B. The effects of a 4-year program promoting bicycle helmet use among children in Quebec. Am J Public Health 1996:86:46-51.

5 Parkin PC, Hu X, Spence L, et al. Evaluation of a subsidy program to increase bicycle helmet use by children of low-income families. Pediatrics 1995;96(2 pt 1):283-7.

6 Lee A. The Bicycle Helmet Initiative Trust: Guidelines for setting up community based cycle helmet programmes. Sheffield: Bicycle Helmet Initiative Trust, 2000.

7 Donner A, Klar N. Design and analysis of cluster randomization trials in health research. London: Arnold, 2000.

8 Ukoumunne OC, Gulliford MC, Chinn S, et al. Methods in health service research. Evaluation of health interventions at area and organisation level. BM 1999;319:376-9.

9 Schieber RA, Sacks JJ. Measuring community bicycle helmet use among children. Public Health Rep 2001;116:113-21.

10 Rivara FP, Thompson DC, Thompson RS. Epidemiology of bicycle injuries and risk factors for serious injury. Inj Prev 1997;3:110-14

11 DiGuiseppi CG, Rivara FP, Koepsell TD, et al. Bicycle helmet use by children. Evaluation of a community-wide helmet campaign. JAMA 1989:262:2256-61.

12 DiGuiseppi CG, Rivara FP, Koepsell TD. Attitudes toward bicycle helmet ownership and use by school-age children. Am J Dis Child 1990; 144:83-6.

13 Towner P, Marvel MK. A school-based intervention to increase the use of bicycle helmets. Fam Med 1992;24:156-8.

14 Dannenberg AL, Gielen AC, Beilenson PL, et al. Bicycle helmet laws and educational campaigns: an evaluation of strategies to increase children's helmet use. Am J Public Health 1993;83:667-74

15 Britt J, Silver I, Rivara FP. Bicycle helmet promotion among low income preschool children. Inj Prev 1998:4:280-3.

16 Wardle S, labal Z. Cycle helmet ownership and wearing; results of a survey in South Staffordshire. J Public Health Med 1998;20:70-7.

17 Rodgers GB. Bicycle helmet use patterns among children. Pediatrics 1996:97:166-73.

18 Sacks JJ, Kresnow M, Houston B, et al. Bicycle helmet use among American children, 1994. Inj Prev 1996;2:258-62.

19 Lajunen T, Rasanen M. Why teenagers owning a bicycle helmet do not use their helemts. J Safety Res 2001;32:323-32.

20 Thompson DC, Thompson RS, Rivara FP. Risk compensation theory should be subject to systematic reviews of the scientific evidence. Inj Prev $2001 ; 7: 86-8$

21 Adams J, Hillman M. The risk compensation theory and bicycle helmets Inj Prev $2001 ; 7: 89-91$

22 Adams J, Hillman M. Bicycle helmets. Risk taking is influenced by people's perception of safety and danger. BM 2001;322:1063-4.

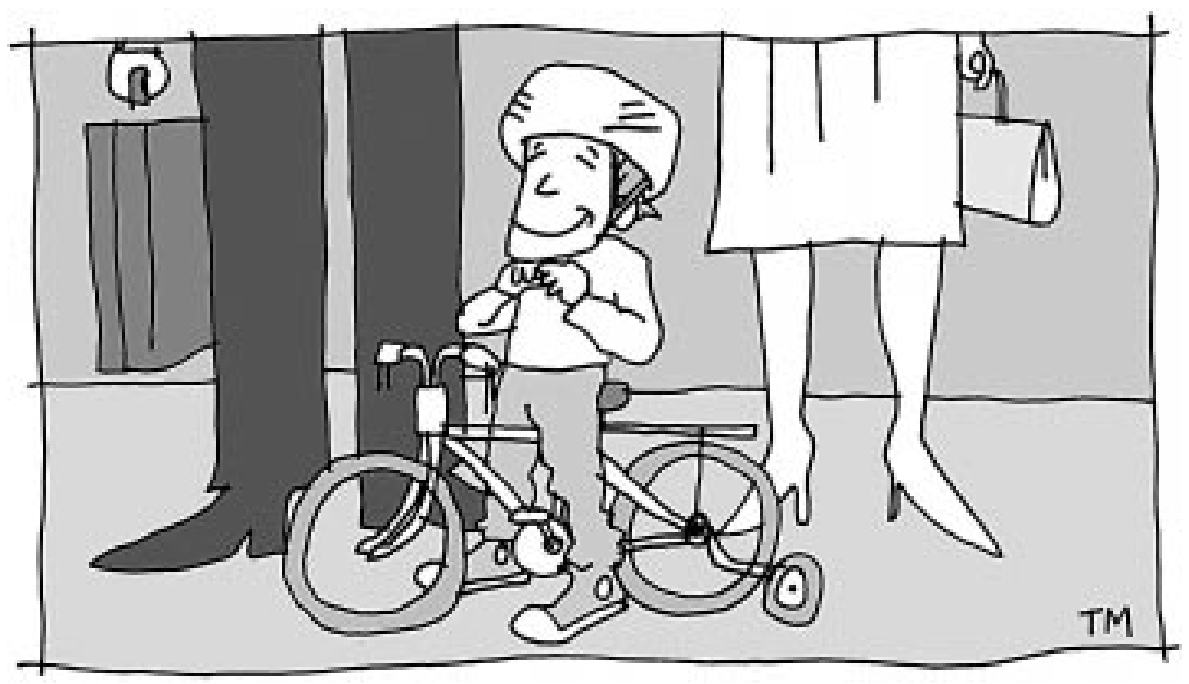

Illustration by Terry McElroy. 